\title{
Comparative Evaluation of Changes in Surface Topography of Protaper Universal and Protaper Gold NiTi Files After Root Canal Preparation in Curved Canal of Molar Teeth: An Optical Profilometery Study
}

\section{Sukhbir Kour*, Trishagni Chaudhury and Pradeep PR \\ Department of Conservative Dentistry and Endodontics, M.R Ambedkar Dental College and Hospital, Bangalore, India}

*Corresponding Author: Sukhbir Kour, Department of Conservative Dentistry and Endodontics, M.R Ambedkar Dental College and Hospital, Bangalore, India.

Received: September 03, 2019; Published: September 12, 2019

DOI: $10.31080 /$ ASDS.2019.03.0638

\begin{abstract}
Objective: The objective of the present in vitro study were to examine the surface topography of intact ProTaper Universal and ProTaper Gold NiTi files and to compare alterations in surface topography of these files before and after root canal preparation in severely curved canals of molar teeth.

Method: Eight ProTaper universal F2 (25/.08) and Eight ProTaper Gold F2 (25/.08) files were included in the present study. In total, $(n=64)$ severely curved canals of molar teeth, with curvature angles ranging between $50^{\circ}$ and $70^{\circ}$, were prepared with ProTaper gold and universal (32 in each group). Quantitative and qualitative analyses of the files' surface deformation were performed by using optical profilometry before and after root canal preparation. The data were analysed with the Student t test at the $5 \%$ significant level by using SPSS 21.0 software.

Result: In the ProTaper Gold group, the qualitative evaluation revealed the presence of cracks and micro cavities after use of the file for root canal preparation, the average roughness, root mean square roughness, and peak to valley height values of the ProTaper Gold group were significantly higher than those of the ProTaper Universal group after root canal preparation $(\mathrm{P}<.05)$.

Conclusion: Within the limitations of the present study, the ProTaper gold files showed significantly higher surface alterations compared with the ProTaper universal files after the preparation of severely curved root canals.
\end{abstract}

Keywords: ProTaper; NiTi; Root Canal; Curved Canal

\section{Introduction}

The application of Nitinol to endodontics was first described in 1975 by Civjan., et al. [1] and in 1988 by Walia., et al. [2]. NickelTitanium instruments offer great flexibility when instrumenting curved canals thus reducing the potential for file separation and canal transportation compared to their stainless-steel predecessors [3]. The ability of a clinician to adequately negotiate the canal system is coincident with the anatomy of the root. The shape and degree of root canal curvature pose a significant limitation in successful cleaning and shaping of root canals. NiTi files systems vary in terms of alloys used, cross-section, blade, and pitch designs taper angles and production methods. In spite of these innovations, management of teeth with curved canals remains a challenge, and the possibility of unexpected fracture of files within the canal remains a fact.

The surface topography of the NiTi files is an important factor in its mechanical behavior. Thus it is prudent to know the surface properties of intact and used NiTi files' to avoid unexpected file fractures. 
In the recent past, many developments such as use of new alloys, changed production methods and thermal treatments improving the mechanical properties of NiTi files are employed to increase the safety and efficiency of NiTi files [4].

ProTaper Universal ${ }^{\mathrm{TM}}$ (PTU, Dentsply Tulsa Dental Specialities) is a NiTi rotary file manufactured with a variable taper over the length of the cutting blades, convex triangular cross sections, and non cutting tips. Later on ProTaper Gold ${ }^{\mathrm{TM}}$ (PTG, Dentsply Tulsa Dental Specialities) instruments was introduced. The PTG files have a design that features identical geometries as PTU but are more flexible and have been developed with proprietary advanced metallurgy. PTG is 300 times more fatigue resistant as compared to PTU [5].

When operating within a curved canal, the rotary instrument experiences alternating tensile and compressive stresses, which lead to deformations and breakage [6]. Many techniques including scanning electron microscope (SEM) [7] and atomic force microscope (AFM) were used to analyze the topographical properties of NiTi files [8]. The noncontact three-dimensional (3-D) optical profilometry is a widely used method in dentistry in analyzing the teeth and composite surfaces, but the method was first used by Ferreira., et al. [9] in examining the surface properties of NiTi files. Ferreira., et al. suggested the use of optical profilometry in analyzing the surface properties of endodontic files because this method makes it possible to analyze wider surfaces without destroying the files when compared with other methods such as SEM or AFM.

The aims of the present study were to examine the surface topographies of intact ProTaper Universal ${ }^{\mathrm{TM}}$ and ProTaper Gold ${ }^{\mathrm{TM}} \mathrm{NiTi}$ rotary files and to compare alterations in the surface topographies of these files after root canal preparation of 4 severely curved mesiobuccal canals of molar teeth.

\section{Materials and Methods}

Eight ProTaper Universal ${ }^{\mathrm{TM}}$ and Eight ProTaper Gold ${ }^{\mathrm{TM}}$ NiTi files were included in the present study. By using an ISO 014 diamond round bur, all the files were marked on the shaft portion before the experiments. With the aid of these marks on the shaft, the same areas on the surfaces of the files were analyzed before and after the root canal preparation.

\section{Root canal instrumentation}

Eight ProTaper Universal ${ }^{\mathrm{TM}}$ and Eight ProTaper Gold ${ }^{\mathrm{TM}}$ files were used in vitro in the present study. In the tests, 64 severely curved canals of molar teeth, with angles of curvature ranging between 50 and 70, were used. To determine the root canal curvature, mesiodistal and buccolingual radiographs were taken according to the parallel technique [10]. Only roots with a fully developed apex and no internal and external resorption were included in the present study. The working length (WL) was determined by measuring the length of \#10 K-file just visible at the apical foramen.S1 file was used to prepare the coronal third of the canal. The canal was irrigated, and a size $10 \mathrm{~K}$-file was used for recapitulation. Both in ProTaper Universal $^{\mathrm{TM}}$ the ProTaper Gold ${ }^{\mathrm{TM}}$ group, S1 (17/02), S2 (20/04), F1 (20/07), and F2 (25/08) files were used till the WL. The preparation was completed with F2 file. PTU \& PTG files were used at a constant speed of $300 \mathrm{rpm}$ and $2.0 \mathrm{Ncm}$ torque. Each file's use was limited to prepare 4 curved canals. After each file change,

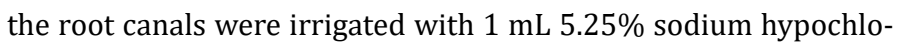
rite. A total of $20 \mathrm{~mL} \mathrm{5.25 \%} \mathrm{sodium} \mathrm{hypochlorite} \mathrm{was} \mathrm{used} \mathrm{in} \mathrm{each}$ sample. After the preparation of the root canals, the instruments were thoroughly rinsed with $5 \mathrm{~mL}$ distilled water. The files were then dried with a soft cotton swab. The used files were ultrasonically cleaned and sterilized by exposing them to 30 psi of pressure for 4 minutes at $134^{\circ} \mathrm{C}$, followed by drying for 15 minutes [11].

\section{Surface evaluation and quantitative analysis}

The ProTaper Universal 25/.08 and ProTaper Gold 25/.08 files were analyzed before and after the root canal preparation by using optical profilometry (Taylor Hobson Precision Talysurf CCI). The surface evaluation of the files was adapted from Ferreira., et al. [9]. The marked points on the shafts of the files were used as reference points. The scanning areas were located $3 \mathrm{~mm}$ coronal from the tip of each file. By using a 50 objective lens, the scanning areas were obtained from the cutting blade and the adjacent portion of the flute. The dimensions of the scanning areas were $170 \times 170 \mathrm{~mm}$. Three amplitude parameters were evaluated in the quantitative analysis: the average roughness $(\mathrm{Sa})$, root mean square roughness $(\mathrm{Sq})$, and peak to valley height $(\mathrm{Sz})$.

\section{Statistical analysis}

The data was first analysed by using the Shapiro-wilk test to verify the assumption of normality. For the statistical analysis of the data, the student ' $\mathrm{t}$ ' test was performed by using SPSS 21.0 (IBMSPSS inc,) software. The statistical significance level was set at $5 \%$. 


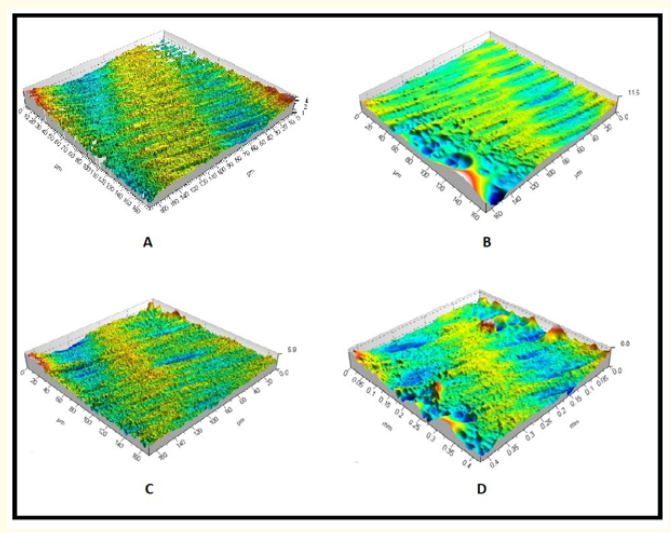

Figure1: Qualitative analysis of cutting blade and flute areas of intact ProTaper universal (A), used ProTaper universal (B), intact ProTaper Gold (C), and used ProTaper Gold (D) NiTi files by using 3-D images.

\section{Results}

In the ProTaper Universal ${ }^{\mathrm{TM}}$ group, the qualitative evaluation of the cutting blade and adjacent flute portion of the file showed minor surface deformation. In the ProTaper Gold ${ }^{\text {TM }}$ group, the qualitative evaluation revealed the presence of cracks and micro cavities after the root canal preparation.

The mean and standard deviations of the Sa,Sq,Sz Values are shown in Table 1. The pre-use ProTaper universal ${ }^{\mathrm{TM}}$ and ProTaper Gold $^{\mathrm{TM}}$ have no significant difference in between the two groups.

In both groups, the tested amplitude parameters (Sa,Sq,Sz) increased after root canal preparation. These parameters were statistically significantly increased in the ProTaper gold group after root canal preparation $(\mathrm{p}<0.5)$.

\begin{tabular}{|l|c|c|c|c|c|c|c|c|}
\hline & \multicolumn{4}{|c|}{ ProTaper Universal } & \multicolumn{3}{c|}{ ProTaper Gold } \\
\hline & \multicolumn{2}{|c|}{ Cutting Blade } & \multicolumn{2}{|c|}{ Flute } & \multicolumn{2}{c|}{ Cutting Blade } & Flute \\
\hline Variable & Before & After & Before & After & Before & After & Before & After \\
\hline $\mathrm{Sa}$ & $21.93 \pm 3.4^{\text {ax }}$ & $34.91 \pm 5.8^{\text {bx }}$ & $40.19 \pm 6.5^{\text {ax }}$ & $53.11 \pm 1.2^{\text {bx }}$ & $27.14 \pm 3.4^{\text {ay }}$ & $41.11 \pm 1.3^{\text {by }}$ & $38.09 \pm 1.7^{\text {ay }}$ & $59.09 \pm 2.9^{\text {by }}$ \\
\hline $\mathrm{Sq}$ & $32.07 \pm 5.0^{\text {ax }}$ & $44.11 \pm 1.8^{\text {bx }}$ & $53.73 \pm 8.3^{\text {ax }}$ & $67.11 \pm 1.8^{\text {bx }}$ & $36.01 \pm 1.8^{\text {ay }}$ & $53.72 \pm 1.5^{\text {by }}$ & $49.14 \pm 2.5^{\text {ay }}$ & $73.12 \pm 3.8^{\text {by }}$ \\
\hline $\mathrm{Sq}$ & $161.5 \pm 2.4^{\text {ax }}$ & $181.21 \pm 3.9^{\text {bx }}$ & $97.57 \pm 7.9^{\text {ax }}$ & $119.32 \pm 1.9^{\text {bx }}$ & $179.0 \pm 4.3^{\text {ay }}$ & $201.74 \pm 5.8^{\text {by }}$ & $105.61 \pm 1.7^{\text {ay }}$ & $131.11 \pm 2.1^{\text {by }}$ \\
\hline
\end{tabular}

Table 1: Mean and standard deviation of Sa, Sq, Sz parameters before and after use of ProTaper universal ${ }^{\mathrm{TM}}$ and ProTaper Gold ${ }^{\mathrm{TM}}$ NiTi instruments (in $\mu \mathrm{m}$ ).

Different superscript letters indicate statistically significant difference at $5 \%$ level (ab for intra group comparison, xy for intergroup comparison)

\section{Discussion}

Adequate cleaning and shaping of severely curved root canal is difficult to achieve and rotary NiTi instruments are at an increased risk of fracture in canals with abrupt curvatures Therefore, use of conventional rotary NiTi instruments should be used with extreme caution.

Nickel titanium instruments are often manufactured through machining of a blank wire. This machine grinding of NiTi files leave the surface with pits, fissures, grooves and multiple cracks [12] which may act as areas of stress concentration, initiating crack formation during clinical use [13]. Sattapan., et al. [14]. Analysed the type of defects in 378 NiTi rotary instruments after clinical use and observed torsional failure in $55.7 \%$ and cyclic fatigue in $44.3 \%$ of all instruments.

So the quality of both the cutting blade and flute area of NiTi files is of clinical interest [15]. Therefore examining these surfaces before and after instrumentation becomes essential to understand the changes that occur in surface topography which leads to instrument fracture [16].

The surface characteristics of NiTi instruments subjected to cyclic fatigue testing have mainly been evaluated using scanning electron microscopy (SEM) [17] or atomic force microscopy (AFM). Drawbacks attributed to SEM include the risk of sample destruction caused by the preparation process and inability to give quantitative 
Comparative Evaluation of Changes in Surface Topography of Protaper Universal and Protaper Gold NiTi Files After Root Canal Preparation in Curved Canal of Molar Teeth: An Optical Profilometery Study

data. AFM can be employed to quantitatively evaluate changes in the surface topography of NiTi files [18]. However, the method requires an ultra-flat and rigid surface but endodontic files are not perfectly flat. In addition, the measurement cycles are lengthy, which increases the time and cost of investigations.

Non-contact optical profilometry has been used by Ferreira., et al. [19] and Uslu G., et al. [20] to study surface topography of NiTi files with good results.

Optical profilometry is a rapid, non destructive and noncontact surface metrology technique. An optical profiler is a type of microscope in which light from a lamp is split into two paths by a beam splitter. One path directs the light onto the surface under test; the other path directs the light to a reference mirror. Reflections from the two surfaces are recombined and projected onto an array detector. This contains information about the surface contours of the test surface.

The present study aimed to analyse the intact surface properties of ProTaper Universal ${ }^{\mathrm{TM}}$ and ProTaper Gold ${ }^{\mathrm{TM}}$ rotary file systems and the changes on the surface properties of files after severely curved root canal preparation.

According to the results obtained, the surface of intact ProTaper Gold $^{\mathrm{TM}}$ files was found to be rougher than that of intact ProTaper Universal $^{\mathrm{TM}}$. Though the difference between the two was not statistically different. It is known that ProTaper Universal ${ }^{\mathrm{TM}}$ and ProTaper Gold ${ }^{\mathrm{TM}}$ files have rougher surfaces because of their production processes. Tuurker., et al. [21] and Fatma., et al. [22] compared the pre-use and post-use surface topography of NiTi files and there results were also similar to our study. They reported that the intact NiTi files had irregular surface properties originating from their production procedures.

In the present study, both ProTaper Universal ${ }^{\mathrm{TM}}$ and ProTaper Gold $^{\mathrm{TM}}$ showed statistically significant increase in surface roughness values after root canal preparation. But the surface of used ProTaper Gold ${ }^{\mathrm{TM}}$ files was found to be statistically significantly rougher than that of used ProTaper Universal ${ }^{\mathrm{TM}}$, Inan., et al. [18] used AFM in examining the surface properties of ProTaper Universal $^{\mathrm{TM}} \mathrm{NiTi}$ rotary files before and after clinical use. Results of study done by Inan., et al. [18] showed that Universal files had higher level of surface deformation and abrasion, and the surface roughness value of used files increased.
In the ProTaper gold group, qualitative evaluation revealed the presence of cracks and micro cavities after the preparation. It can be said that heat treatment of the alloy in PTG instruments may predispose the instruments to plastic deformation and disruption of cutting edges during use, reducing its cutting ability. This finding corroborates previous literature that showed plastic deformation of instruments after clinical use as a result of the thermal pre-treatment of the alloy [23].

Ferreira., et al. [9] qualitatively and quantitatively examined the changes in cutting blades and grooves of Wave One files after use in resin blocks. They reported deformations on cutting blades and grooves of files and increase in their surface roughness values after use in artificial canal.

Several factors could have a substantial effect on the topographical properties of NiTi rotary instruments including cross-sectional design, chemical composition of the alloy and thermo mechanical process applied during manufacturing [24].

Although the PTG and PTU have similar cross section design, PTG has torsional value of $(2.77 \pm 0.21 \mathrm{~N} . \mathrm{cm})$ and PTU has value of (3.51 $\pm 0.27 \mathrm{~N} . \mathrm{cm})$ respectively. PTG had a significantly lower torsional resistance than PTU [25]. It could be attributed to the 2- stage transformation behaviour and the high Af temperatures from which PTG is produced; as this material has greater flexibility $[26,27]$ with an elastic modulus lower than that of the austenitic phase [14], Consequently, it could be supposed that the martensitic NiTi wire allows a greater amount of deformation at a similar torque than austenitic NiTi alloy [14].

It has been reported that the average root dentine micro hardness is 67 VHN [28]. Accordingly, the hardness of PTG and PTU instruments should be appropriate (approximately 5 times harder than dentine) for shaping and cleaning canal walls. PTG have a Vickers harness no. of $290.85 \pm 19.30$ VHN whereas PTU has a Vickers harness no. of $331.45 \pm 11.43$ VHN. PTG instruments are significantly softer than PTU. PTU had higher VHN values compared with PTG [15]. High surface micro hardness indicates improvement in the cutting efficiency and wear resistance of NiTi rotary instruments. PTG has less resistance to torsional stress and micro hardness compared with PTU. This decreased micro hardness of PTG Files indicates they will be have less resistance to wear and tear and thus will show higher surface deformations as compared to PTU [29]. 
It has been reported that the PTG instruments revealed 2-stage transformation behaviour (austenite [A]-Rphase-martensite [M]) and also have high Af temperatures due to heat treatment [17]. The martensitic transformation occurs due to a single-stage transformation (A-M) or a 2-stage transformation (A-R-M) depending on the thermo mechanical treatments [30] The 1-stagetransformation (A-M) happens in Ni-rich NiTi alloys, whilst 2-stage transformation (A-R-M) happens after additional heat treatment. The heat treatment forms finely dispersed $\mathrm{Ti} 3 \mathrm{Ni} 4$ precipitates in the austenitic matrix [20]. Consequently, the $\mathrm{R}$ phase is formed in preference to martensite due to the presence of Ti3Ni4 fine particles. However, the alloy needs additional cooling to form martensite, and hence, martensitic transformation occurs in 2 steps (A-R-M) [20]. In addition, it has been reported that the PTG instruments have high Af temperatures.

The crack propagation mechanism in martensitic phase presents a large number of highly branched cracks that propagate very slowly because the energy absorbing crystalline structure provides a damping effect. So the surface of PTG instrument showed more no of cracks. Whereas the austenitic NiTi exhibits fewer surface crack nucleation sites and crack propagation is much rapid. So it correlates with our study where ProTaper Universal showed less no of surface cracks when compared to ProTaper Gold

\section{Conclusion}

Within the limitations of the present study, the ProTaper Gold files showed a significantly higher level of surface deformation compared with the ProTaper Universal files after preparation of severely curved root canals. Hence heat treatment of this PTG file may have increased it cyclic fatigue resistance as reported by various studies but heat treatment could not show any significant difference in preventing surface topography changes.

\section{Bibliography}

1. Civjan S., et al. "Potential applications of certain nickel-titanium (nitinol) alloys”. Journal of Dental Research 54.1 (1975): 89-96.

2. Walia H., et al. "An initial investigation of the bending and torsional properties of Nitinol root canal files". Journal of Endodontics 14.7 (1988): 346-351.

3. Sattapan B., et al. "Torque during canal instrumentation using rotary nickel-titanium files". Journal of Endodontics 26.3 (2000): 156-160.
4. Park SY., et al. "Dynamic torsional resistance of nickel-titanium rotary instruments". Journal of Endodontics 36.7 (2010): 1200-1204.

5. Hieawy A., et al. "Phase transformation behavior and resistance to bending and cyclic fatigue of ProTaper Gold and ProTaper Universal instruments". Journal of Endodontics 41.7 (2015): 1134-1138.

6. Pedullà E., et al. "Influence of continuous or reciprocating motion on cyclic fatigue resistance of 4 different nickel-titanium rotary instruments". Journal of Endodontics 39.2 (2013): 258261.

7. Alapati SB., et al. "SEM observations of nickel-titanium rotary endodontic instruments that fractured during clinical use". Journal of Endodontics 31.1 (2005): 40-43.

8. Saglam BC., et al. "Effects of irrigation solutions on the surface of ProTaper instruments: a microscopy study". Microscopy research and technique 75.11 (2012): 1534-1538.

9. Ferreira FG., et al. "Qualitative and quantitative evaluation of human dental enamel after bracket debonding: a noncontact three-dimensional optical profilometry analysis". Clinical oral investigations 18.7 (2014): 1853-1864.

10. Kosti E., et al. "Effect of root canal curvature on the failure incidence of ProFile rotary Ni-Ti endodontic instruments". International Endodontic Journal 44 (2011): 917-925.

11. Mize SB., et al. "Effect of sterilization on cyclic fatigue of rotary nickel-titanium endodontic instruments". Journal of Endodontics 24 (1998): 843-847.

12. Alapati SB., et al. "Scanning electron microscope observations of newand used nickel-titanium rotary files". Journal of Endodontics 29.10 (2003): 667-669.

13. Kuhn G., et al. "Influence of structure on nickel-titanium endodontic instruments failure". Journal of Endodontics 27.8 (2001): 516-520.

14. Sattapan B., et al. "Defectsin rotary nickel-titanium files after clinical use". Journal of Endodontics 26.3 (2000): 161-165.

15. Hanan AR., et al. "Surface characteristics ofreciprocating instruments before and after use - a SEManalysis". Brazilian Dental Journal 26.2 (2015): 121-127

16. Pessoa OF., et al. "Cyclic fatigue resistanceof rotary NiTi instruments after simulated clinical use incurved root canals". Brazilian Dental Journal 24.2 (2013): 117-120 
17. Tripi TR., et al. "Defects in GT rotary instruments after use: an SEM study". Journal of Endodontics 27 (2001): 782-785.

18. Inan U., et al. "Evaluation of the surface characteristics of used and new ProTaper instruments: an atomic force microscopy study". Journal of Endodontics 33 (2007): 1334-1337.

19. Ferreira F., et al. "A new method for the assessment of the surface topography of NiTi rotary instruments". International Endodontic Journal 50.9 (2017): 902-909.

20. Uslu G., et al. "Comparison of Alterations in the Surface Topographies of HyFlex CM and HyFlex EDM Nickel-titanium Files after Root Canal Preparation: A Three-dimensional Optical Profilometry Study". Journal of Endodontics 44.1 (2018): 115119.

21. Turker SA., et al. "The effect of glide path on the surface quality of new and used rotary and reciprocating single files: OneShape versus WaveOne". Scanning 36 (2014): 608-613.

22. Fatma Y and Ozgur U. "Evaluation of surface topography changes in three NiTi file systems using rotary and reciprocal motion: an atomic force microscopy study". Microscopy Research and Technique 77 (2014): 177-182.

23. Shen Y., et al. "HyFlex nickel-titanium rotary instruments after clinical use: metallurgical properties". International Endodontic Journal 46 (2013): 720-729.

24. Park SY., et al. "Dynamic torsional resistance of nickel-titanium rotary instruments". Journal of Endodontics 36.7 (2010): 1200-1204.

25. ElnaghyAM and Elsaka SE. "Mechanical properties of ProTaper Gold nickel-titanium rotary instruments". International Endodontic Journal 49.11 (2016): 1073-1078.

26. Otsuka K and Ren X. "Physical metallurgy of Ti-Ni-based shape memory alloys". Progress in materials science 50.5 (2005): 511-678.

27. Hieawy A., et al. "Phase transformation behavior and resistance to bending and cyclic fatigue of ProTaper Gold and ProTaper Universal instruments". Journal of Endodontics 201541 (7): 1134-1138.

28. Lewinstein I and Grajower R. "Root dentin hardness of endodontically treated teeth". Journal of Endodontics 7.9 (1981): 421-422.
29. Gao Y., et al. "Evaluation of the impact of raw materials on the fatigue and mechanical properties of ProFile Vortex rotary instruments". Journal of Endodontics 38.3 (2012): 398-401.

30. Otsuka K and Ren X. "Physical metallurgy of Ti-Ni-based shape memory alloys". Progress in Materials Science 50.5 (2005): 511-678.

Volume 3 Issue 10 October 2019

(C) All rights are reserved by Sukhbir Kour., et al. 